\title{
Comparative study of the repair of cracked plates with two different composite patches
}

\author{
Moulgada Abdelmadjid \\ LTRI, Department of mechanical Engineering, University of Ibn Khaldoune Tiaret, City Zaaroura BP 7814000 Tiaret, Algeria \\ amoulgada@hotmail.fr
}

Zagane Mohammed El Sallah

University of Ibn Khaldoune Tiaret, City Zaaroura BP 7814000 Tiaret, Algeria

LMPM, Department of Mechanical Engineering, University of Djillali Liabes Sidi Bel Abbes, Algeria

salab_cao@yahoo.fr

Sahli Abderahmane, Ait kaci Djafar, Zahi Rachid

LMPM, Department of Mechanical Engineering, University of Djillali Liabes Sidi Bel Abbes, Algeria

sabliabderahmen@yaboo.fr,Aitkaci07@yahoo.fr, zabiracbid72@yahoo.fr

ABSTRACT. The aim of this study is to analyze the behavior of a crack with and without reinforcement by a composite patch of an aluminum plate in mode I using the finite element method. The repair patch is boron / epoxy and Carbon / epoxy, which are used with great success by many researchers For the distribution of the stresses according to the various loadings, we can conclude that the effect of repair by patch in composite is very distinct, considering the intensities of stresses which decrease for each repair corresponding to the plate not repaired, therefore, the patch in composite dampens the stress field induced at the crack tip and causes a reduction in stresses. The repair with the Bore / epoxy composite patch is more effective than the Carbon/Epoxy patch, this is due to the mechanical properties and the various characteristics specific to boron/Epoxy which gives very significant and very effective results for the repair.

KEYWORDS. Crack; Finite element method; Stresses; Composite; Adhesive.

\section{OPEN ACCESS}

Citation: Moulgada, A ,Zagane, M.E., Sahli.,A, Ait kaci, D, Zahi, R.. Comparative study of the repair of cracked plates with two different composite patches, Frattura ed Integrità Strutturale, 53 (2020) 187-201.

Received: 20.03 .2020

Accepted: 19.04 .2020

Published: 01.07.2020

Copyright: (c) 2020 This is an open access article under the terms of the CC-BY 4.0 , which permits unrestricted use, distribution, and reproduction in any medium, provided the original author and source are credited.

\section{INTRODUCTION}

$\mathrm{T}$ he lifetime of cracked structures risks having crucial damage or fatigue of the material, either by the propagation of cracks or by the singularity in the vicinity of the crack head; to avoid these risks of rupture or fatigue of the materials, bonding by composite patch remains a clear and adequate solution to be able to prolong the life of these structures, this repair by patch, has proven these experimental results and allows an effective gain and concrete, but this repair depends 
on the mechanical properties of the patch in question and the results vary from one composite to another. In 1998, it was shown by Pook [1] that the assumption that crack growth is in mode I leads to geometric constraints on permissible fatigue crack paths. Polymer matrix composites are particularly vulnerable not only to commissioning stresses but also to environmental media. These composites are widely used in aircraft structures, civil engineering, hydrocarbon electronics. Nevertheless, these composites are, over time, sensitive to macroscopic failure, A phenomenon resulting from microscopic damage (crack formation) by the degradation of thermomechanical properties [2]. In other works, the volume fraction of the reinforcement, its distribution and its size significantly affect the resistance to degradation [3-7]. Some work has used the Puck damage criterion to analyze the initiation and propagation of cracks in the fiber and/or matrix. The behavior of these cracks determines the predominant fracture mode of the composite. They also show that the presence of defects in the direction of crack propagation accelerates its instability [8]. Other authors used the finite element method FEM and XFEM for analysis of crack initiation and propagation in composites. The finite element method used for the study of crack behavior and damage in composites [9-11]. The innovative idea is to bring geometric improvements to an assembly system type Aluminum/Aluminum 2024-T3 bonded with an adhesive ADEKIT A-140; the geometric improvements presented are beneficial and the results show a good reduction of the stress concentration along overlap length [12]. Due to the nature of their polymer matrices, the modeling of their mechanical behavior is very delicate to implement. These composites reinforced with long fibers are strongly anisotropic and lead in the case of an elastic approach to a large number of coefficients to be determined in the case of a laminate [13]. Crack growth study under thermo-mechanical loads: parametric analysis for 2024 T3 aluminum alloy, it is important to note that the "strong" coupling between temperature and mechanical variables (stress, strain and damage) and damage) is very important [14]. Among the methods of repairing damaged structures, bonding a composite patch is currently the most used. In particular, composite patch repair has shown its effectiveness in the field of aeronautics and maritime structures [15]. A numerical simulation based on 3D in order to investigate the effect of crack-front shape on the stress intensity factor and fatigue crack growth behavior of center cracked aluminum plate repaired asymmetrically with bonded composite patch [16]. Without omitting the effect of the parameters related to the adhesive such as the thickness and the type of the glue that have provoked several searches as for example in [17-19]. The structural behavior investigated through three-point bending test, and it was found that the flexural behavior was affected by both the investigated factors; in fact, the maximum flexural load diminished incrementing the number of layers and inserting an adhesive layer at the metal/composite interface [20]. A need timely reveal operational damages and technological defects requires a prompt control of states of structures and their consequent repairs aimed at service life extension [21-26]. The experimental study of inelastic deformation and fracture of specimens made from layer composite materials with prior introduced technological defects related to a possible inappropriate compacting and inappropriate bonding of material layers at a given restricted domain [27]. The SED has been considered as a parameter able to control fracture in some previous contributions and can easily take into account also coupled threedimensional effects [28]. Our study is characterized by a numerical simulation using Abaqus 6.14 software on a laterally cracked plate and repaired by two composite patches. The repair patches are boron/epoxy and carbon/epoxy, which used with great success by many researchers. The Von Mises stresses, the normal stresses and shear stresses are highlighted in this study, and then a comparison of the different stresses for the unrepaired and repaired plate. Finally, the integral J will be cleared in both cases.

\begin{tabular}{lccc}
\hline Materials & $\begin{array}{c}\text { Aluminum } \\
\text { Plate }\end{array}$ & Patch & Adhesive \\
Length $\mathrm{H}(\mathrm{mm})$ & 250 & 127 & 127 \\
Width $\mathrm{W}(\mathrm{mm})$ & 127 & 63.5 & 63.5 \\
Thickness e $(\mathrm{mm})$ & 3.0 & 2.0 & 0.1 \\
\hline
\end{tabular}

Table 1: Dimensions of the plate, adhesive layer and patch

\section{PRESENTATION OF MODEL}

$\mathrm{I}$ $\mathrm{n}$ this modeling, we consider a thin rectangular plate of aluminum 2024-T3, with composites patch, in first time we used a patch Boron/ epoxy, in second time, we used a composite Carbon/epoxy having the following dimensions in Tab. 1. An initial lateral crack of $5 \mathrm{~mm}$ in length in the plate perpendicular to the loading direction. The plate considered 
stressed in uni-axial tension in the vertical direction "y" under the applied stress of varying amplitude $\sigma(20,40,60,80$ and $100 \mathrm{MPa}$ ). The plate was repaired by an external rectangular patch.

\section{Material properties}

The mechanical characteristics of the assembly materials (plate, patch and the adhesive layer) are shown in the Tab. 2 and 3, the Fig.1 shows the geometric model of the structure used.
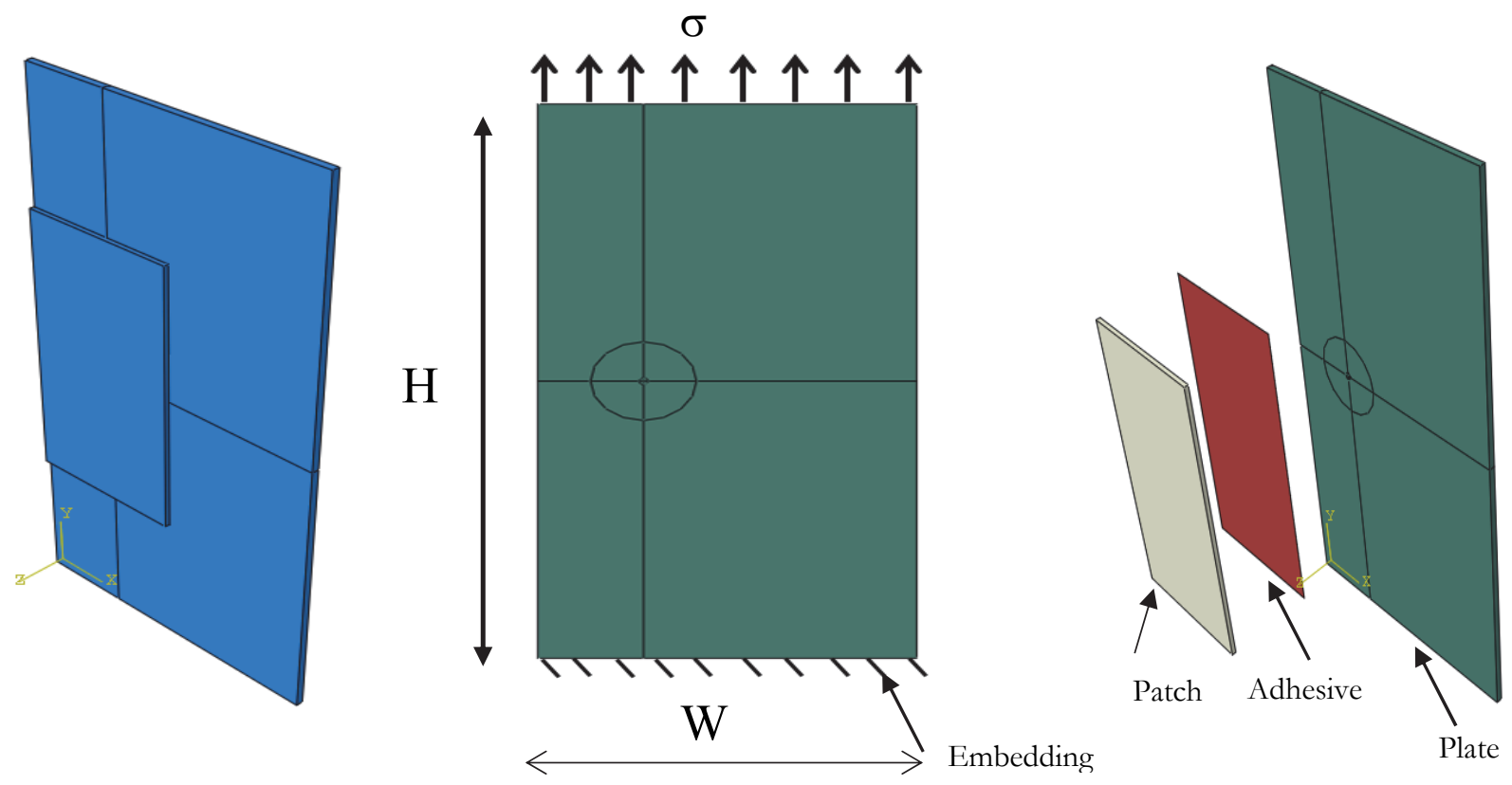

Figure 1: Geometrical model of the repaired plate.

\begin{tabular}{llllllllll}
\hline Material & $\mathrm{E}_{1}(\mathrm{GPa})$ & $\mathrm{E}_{2}$ & $\mathrm{E}_{3}$ & $\mathrm{G}_{12}(\mathrm{MPa})$ & $\mathrm{G}_{13}$ & $\mathrm{G}_{23}$ & $\nu_{12}$ & $\nu_{13}$ & $\nu_{23}$ \\
Bore/Epoxy & 109.0 & 8.819 & 8.819 & 4315 & 4310 & 3200 & 0.342 & 0.342 & 0.38 \\
Carbone/Epoxy & 138.0 & 9.500 & 9.500 & 5200 & 5200 & 1450 & 0.28 & 0.28 & 0.40 \\
\hline
\end{tabular}

Table 2: Mechanical properties of the boron/epoxy and the carbon/epoxy composite

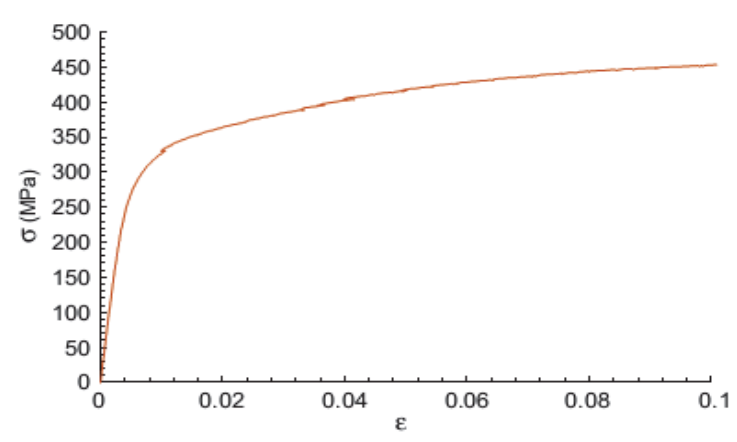

(a)

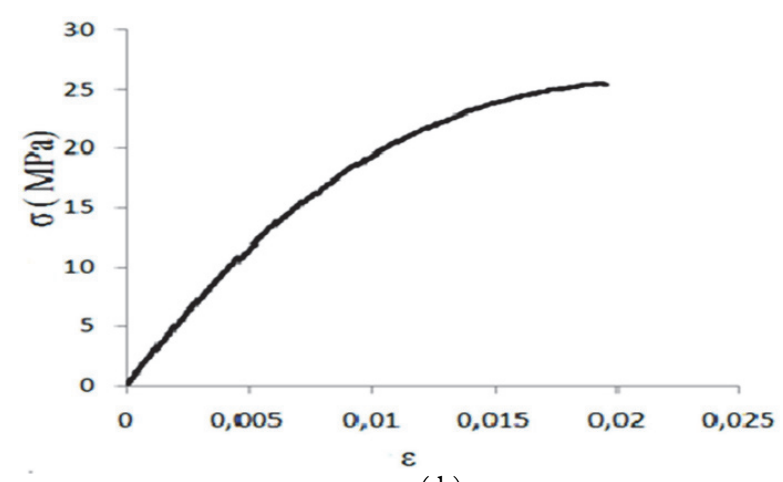

(b)

Figure 2: Stress-strain curve: a) - Aluminum plate 2024 T3 b) -Adekit A140 adhesive [29]

Four (04) stacking sequences have been put on the proposed composite, namely Boron / Epoxy and Carbon/Epoxy that is distributed as follows: $\left(0^{\circ} / 45^{\circ} / 60^{\circ} / 90^{\circ}\right)$ Fiber orientation. 


\begin{tabular}{lccc}
\hline Materials & $\begin{array}{c}\text { E:Young modulus } \\
(\mathrm{GPa})\end{array}$ & $\begin{array}{c}\text { G:Shear modulus } \\
(\mathrm{GPa})\end{array}$ & v: Poisson coefficient \\
Aluminum 2024-T3 & 69 & 36.92 & 0.3 \\
Adhesive: Adekit A-40 & 2.69 & 0.99 & 0.3 \\
\hline
\end{tabular}

Table 3: Mechanical properties of Aluminum 2024-T3 and Adekit A140 Adhesive [17]

\section{FINITE ELEMENT MODEL}

he finite element analysis of the configuration of the repaired plate (shown in Fig. 3) is done using the calculation code ABAQUS [30]. The structure of the layers of the laminate (patch) is in fact a three-dimensional structure. A three-dimensional finite element model of such a structure has several degrees of complexity. A refined mesh is presented at the adhesive layer and plates to determine the maximum stresses.

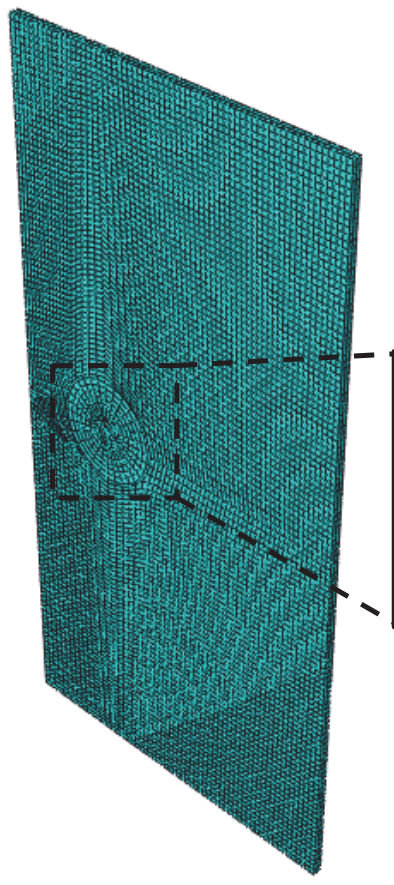

(a)

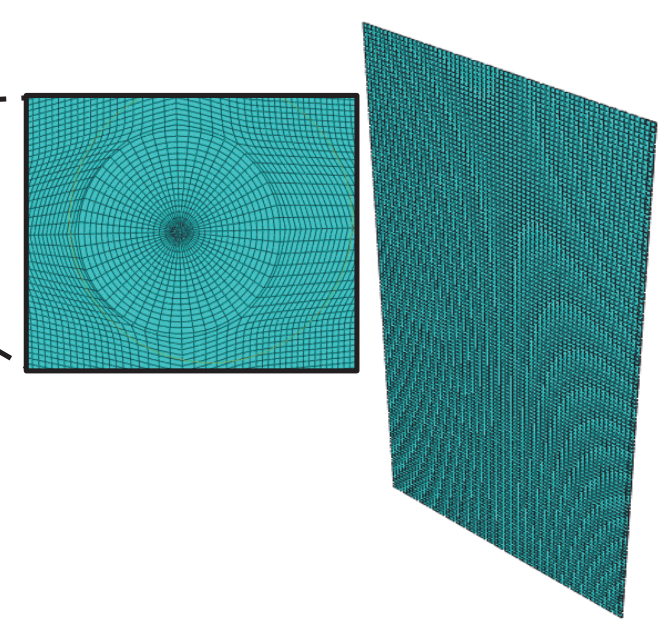

(b) (c)

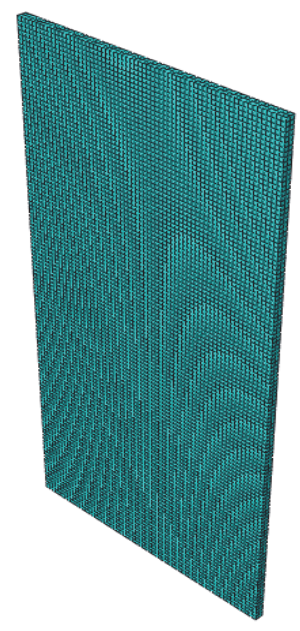

(d)

Figure 3: Geometrical model and mesh of the structure: a) Plate, b) Head of crack, c) Adhesive and d) patch.

The adhesive is modeled as a third layer. In the finite element model, the nodes are common between each three-dimensional structure so that there is a continuity of the strain and the stress. The elements used in the modeling of the set are C3D20R, A 20-node quadratic brick. A fine mesh was adopted in the area around the crack. The number of elements used in this study are 85062 elements in the Aluminum plate, 16256 elements in the composites patch and 8128 elements in the adhesive layer.

\section{RESULTS AND DISCUSSIONS}

7 he analysis of the stress distribution in the bonded assemblies is essential in order to predict the level of stress intensity

for each substrate. Almost all the applied load will be transmitted to the adhesive which is the weak link of the structure seen these weak mechanical properties comparing to those of the plates. Our investigation will be focused on 
extracting all the stresses induced in the structure due to the increasing tensile loading whether for normal or tangential stresses in order to predict the most optimal stresses to avoid the phenomenon of shearing or detachment of the patch.

\section{Von Mises stresses}

In this part of the study, we presented the stresses induced in the plate which is stressed in tension in the two different directions, and with the boundary conditions imposed, in order to make a comparison of the plate not repaired with this same plate repaired by composite patch which is Boron/epoxy and carbon/epoxy, and see the effect of the reduction of the stress intensities requested in this plate.

\begin{tabular}{|l|}
\hline S, Mises \\
SNEG, (fraction = -1.0) \\
(Avg: 75\%) \\
$+2.374 \mathrm{e}+03$ \\
$+2.176 \mathrm{e}+03$ \\
$++1.978 \mathrm{e}+03$ \\
$+1.780 \mathrm{e}+03$ \\
$+1.582 \mathrm{e}+03$ \\
$+1.385 \mathrm{e}+03$ \\
$+1.187 \mathrm{e}+03$ \\
$+9.890 \mathrm{e}+02$ \\
$+7.912 \mathrm{e}+02$ \\
$+5.934 \mathrm{e}+02$ \\
$+3.956 \mathrm{e}+02$ \\
$+1.978 \mathrm{e}+02$ \\
$+1.432 \mathrm{e}-02$ \\
\hline
\end{tabular}
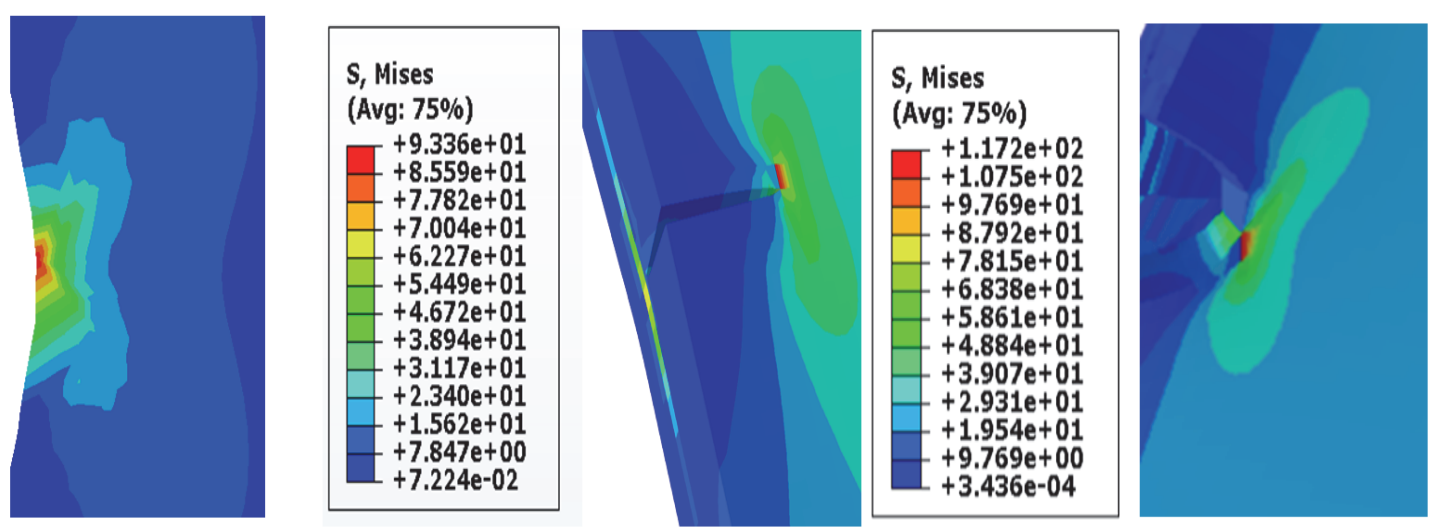

\section{«Load 40 MPa»}
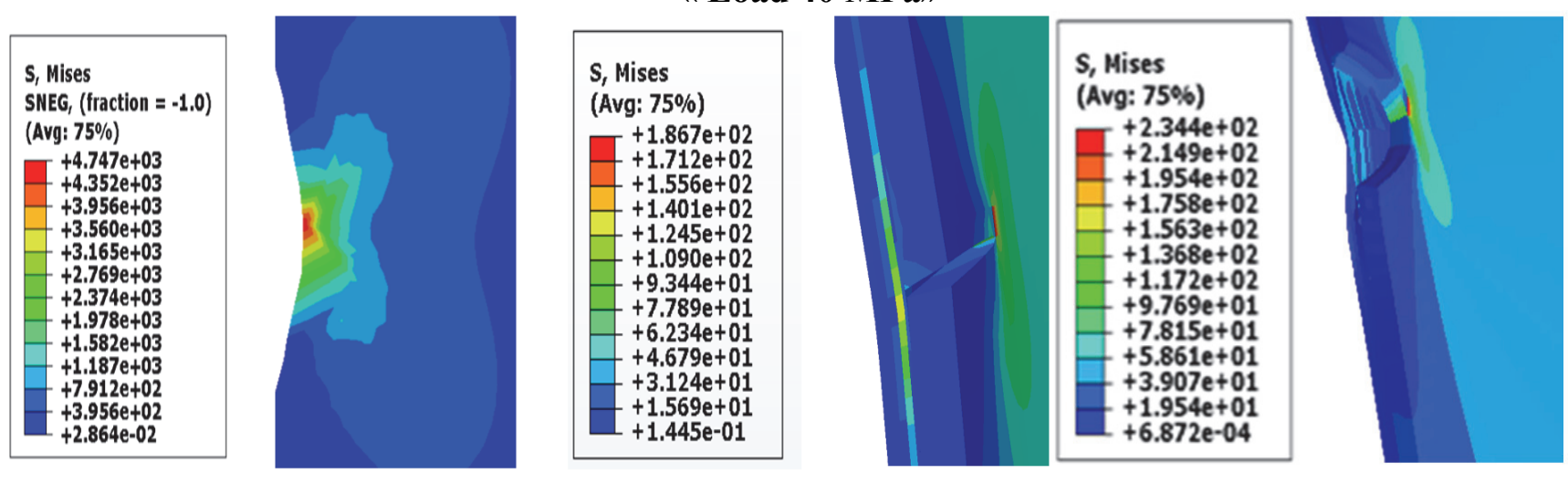

\section{«Load 60 MPa»}

\begin{tabular}{|l|}
\hline S, Mises \\
SNEG, (fraction = -1.0) \\
(Avg: 75\%) \\
$+7.121 \mathrm{e}+03$ \\
$+6.527 \mathrm{e}+03$ \\
$++5.934 \mathrm{e}+03$ \\
$+5.341 \mathrm{e}+03$ \\
$++4.747 \mathrm{e}+03$ \\
$++4.154 \mathrm{e}+03$ \\
$+3.560 \mathrm{e}+03$ \\
$+2.967 \mathrm{e}+03$ \\
$+2.374 \mathrm{e}+03$ \\
$+1.780 \mathrm{e}+03$ \\
$+1.187 \mathrm{e}+03$ \\
$+5.934 \mathrm{e}+02$ \\
$+4.296 \mathrm{e}-02$ \\
\hline
\end{tabular}
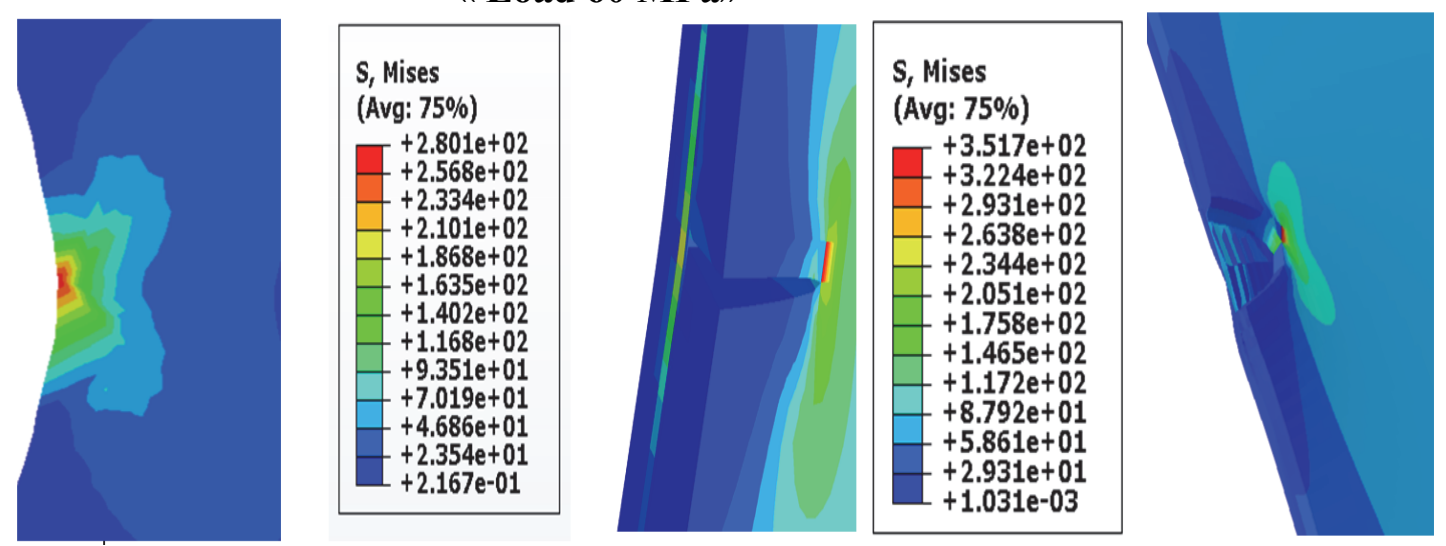
«Load 80 MPa»

\begin{tabular}{|l|}
\hline S, Mises \\
SNEG, (fraction = -1.0) \\
(Avg: 75\%) \\
$+9.494 \mathrm{e}+03$ \\
$++8.703 \mathrm{e}+03$ \\
$++7.912 \mathrm{e}+03$ \\
$++7.121 \mathrm{e}+03$ \\
$+6.330 \mathrm{e}+03$ \\
$++5.538 \mathrm{e}+03$ \\
$++4.747 \mathrm{e}+03$ \\
$+3.956 \mathrm{e}+03$ \\
$+3.165 \mathrm{e}+03$ \\
$++2.374 \mathrm{e}+03$ \\
$+1.582 \mathrm{e}+03$ \\
$+7.913 \mathrm{e}+02$ \\
$+5.728 \mathrm{e}-02$ \\
\hline
\end{tabular}
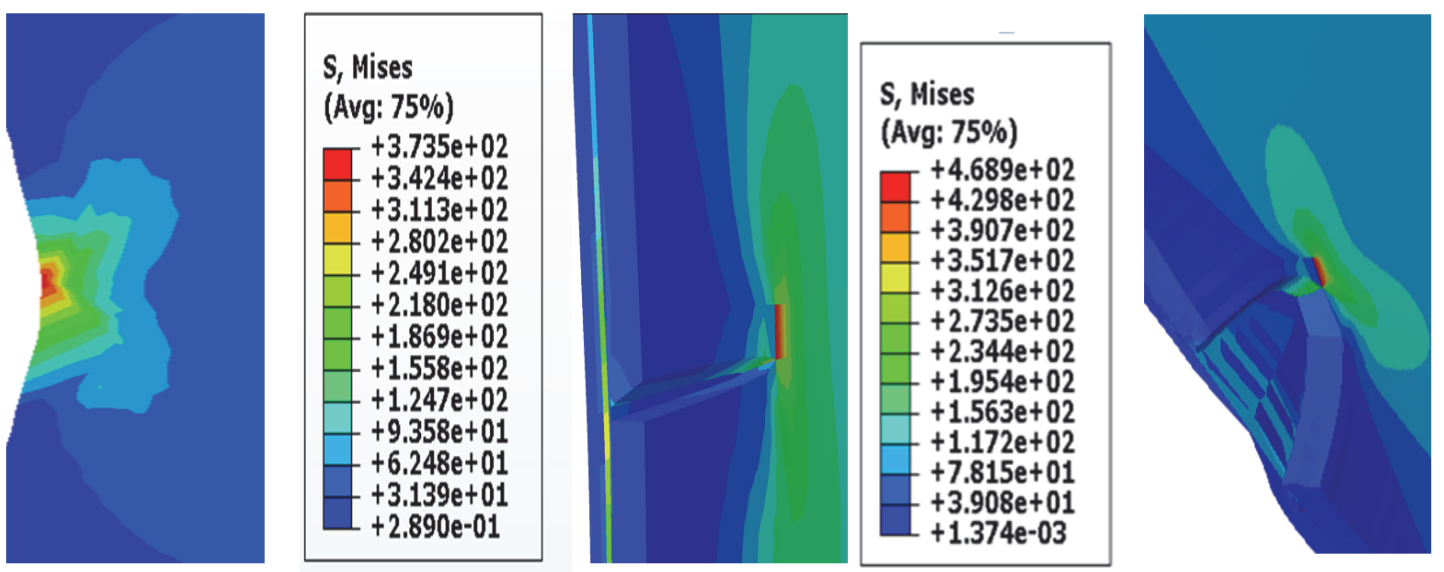

«Load 100 MPa»

\begin{tabular}{|l|}
\hline S, Mises \\
SNEG, (iraction = -1.0) \\
(Avg: 75\%) \\
$+1.187 \mathrm{e}+04$ \\
$+1.088 \mathrm{e}+04$ \\
$+9.890 \mathrm{e}+03$ \\
$++8.901 \mathrm{e}+03$ \\
$+7.912 \mathrm{e}+03$ \\
$+6.923 \mathrm{e}+03$ \\
$+5.934 \mathrm{e}+03$ \\
$+4.945 \mathrm{e}+03$ \\
$+3.956 \mathrm{e}+03$ \\
$+2.967 \mathrm{e}+03$ \\
$+1.978 \mathrm{e}+03$ \\
$+9.891 \mathrm{e}+02$ \\
$+7.160 \mathrm{e}-02$ \\
\hline
\end{tabular}

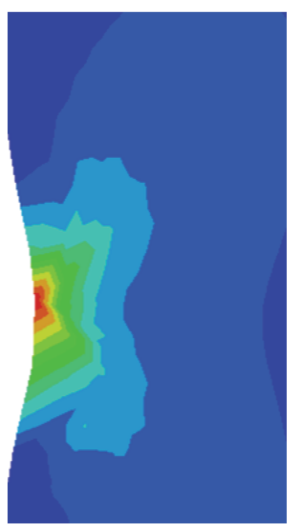

a)

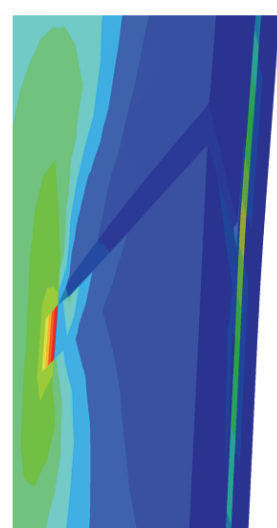

b)
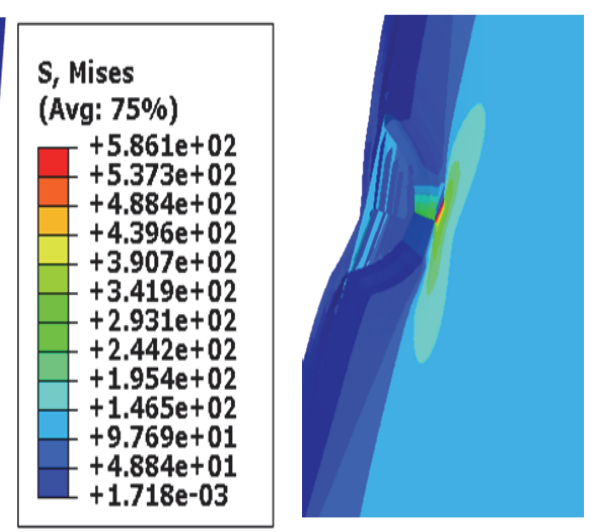

c)

Figure 4: Distribution of the Von Mises equivalent stresses: a) Plate not repaired b) Plate repaired Boron epoxy c) Plate repaired Carbon epoxy.

The first remarks drawn by these stress distributions leads us to conclude that the unrepaired plate is stressed by very significant stresses especially at the crack tip and the affected area is very large, namely this confined plastic area, while, in the presence of the composite which is a very stress-absorbing element, and after the repair of this plate, these equivalent stresses of Von Mises have a very distinct reduction in its intensity, hence the importance of this repair by this boron / epoxy composite, and by carbon / epoxy, therefore, there is a relaxation of the stresses.

The reduction of the stress intensities in the event of repair is very remarkable relative to the unrepaired plate for the equivalent stresses of Von Mises, this proves that the composite patch absorbs and dampens all the stresses at the same time by slowing the crack propagation and make the stress field lower, for a confined area in the vicinity of the crack head and to avoid its initiation, this repair in composite patch prevents the propagation of the crack and allows the longitivity of life for crack.

The gain in repair is very distinct by the two composites due to their effectiveness, hence, the most effective and efficient composite is boron/epoxy by its important mechanical properties, which leaves all the stresses to be reduced and to be absorbed, then the carbon/epoxy, which in turn has interesting properties and leaves the stresses to be reduced.

For the cases of repair by these two patches, the maximum stress reached does not even exceed $600 \mathrm{MPa}$ for a loading of $100 \mathrm{MPa}$, while for the not repaired plate, this stresses reaches around $11870 \mathrm{MPa}$, and this proves the absorption of these stresses by repair. 

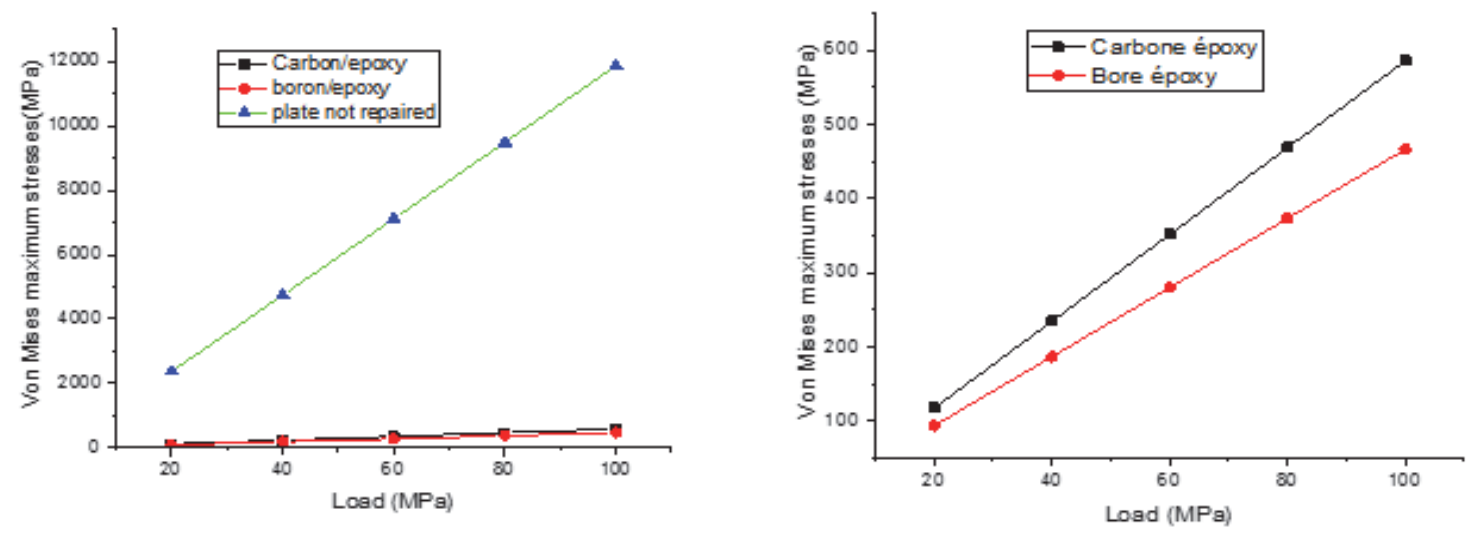

Figure 5: Variation of the maximum equivalent stresses of Von Mises according to the various loadings.

Normal Stresses $\sigma \times x$

In this part, we will make a direct comparison for the different normal stresses $\sigma \mathrm{xx}$ in order to distinguish the effect of the repair by the composite patch from the plate having a lateral crack stressed by tensile loads.

We note that the area of the repaired plate is strongly affected by very important stresses compared to that repaired, we conclude that there is a very remarkable reduction for this repaired plate, for that, and for fairly low load, such as $20 \mathrm{MPa}$ and $40 \mathrm{MPa}$, their effects on the repaired plaque are almost weak. It is noted that the reduction of the normal stresses is less important unlike the boron/epoxy patch, since approximately the crack head, which knows an opening of its lips, and creates a stress field around its head proves a gain quite significant by this repair, hence the effectiveness of the Bore / epoxy patch compared to the carbon / epoxy patch, by its very important mechanical properties which make it possible to reduce the stresses induced at the crack head and give the plate a certain rigidity in order to be able to withstand different stresses and increase its lifespan.

\section{«Lad 20 MPa»}

\begin{tabular}{|l|}
\hline S, S11 \\
SNEG, (fraction = -1.0) \\
(Avg: 75\%) \\
$+1.325 \mathrm{e}+03$ \\
$+1.207 \mathrm{e}+03$ \\
$+1.090 \mathrm{e}+03$ \\
$++9.725 \mathrm{e}+02$ \\
$+8.550 \mathrm{e}+02$ \\
$+7.375 \mathrm{e}+02$ \\
$+6.200 \mathrm{e}+02$ \\
$+5.025 \mathrm{e}+02$ \\
$+3.850 \mathrm{e}+02$ \\
$+2.675 \mathrm{e}+02$ \\
$+1.500 \mathrm{e}+02$ \\
$+3.245 \mathrm{e}+01$ \\
$-8.506 \mathrm{e}+01$ \\
\hline
\end{tabular}
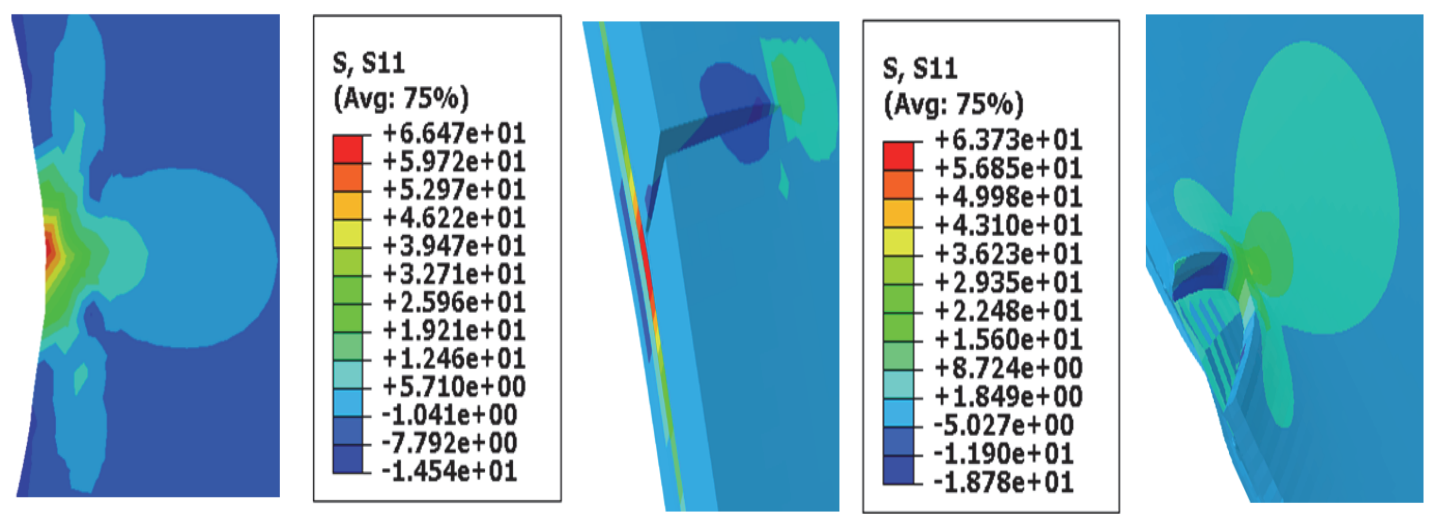

\section{«Load 40 MPa»}
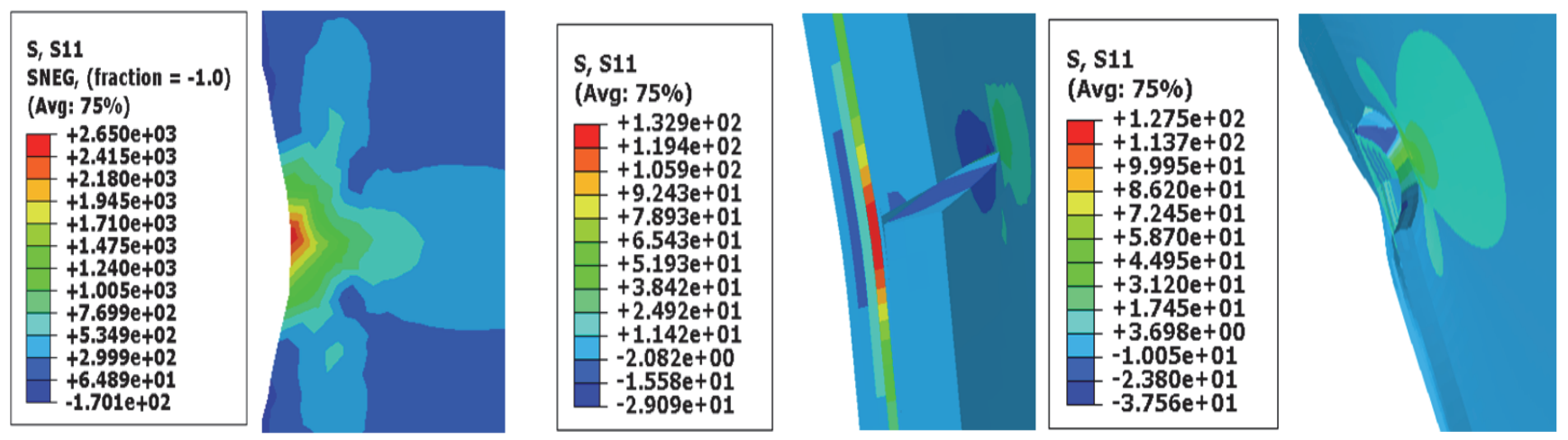


\section{«Load 60 MPa»}
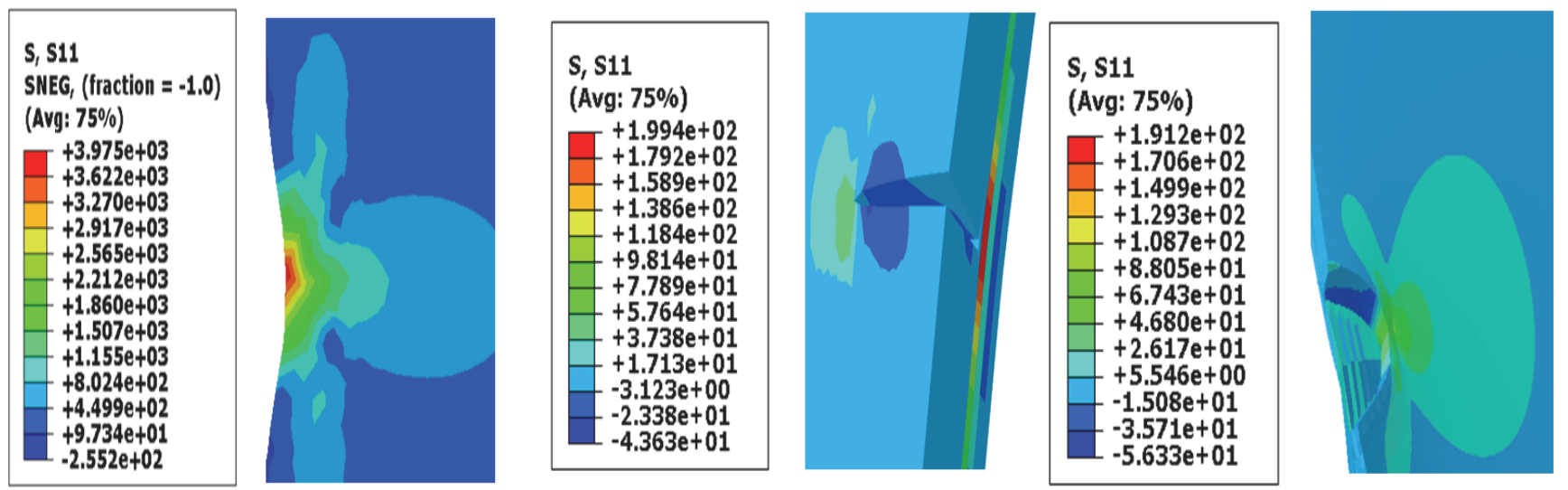

«Load 80 MPa»
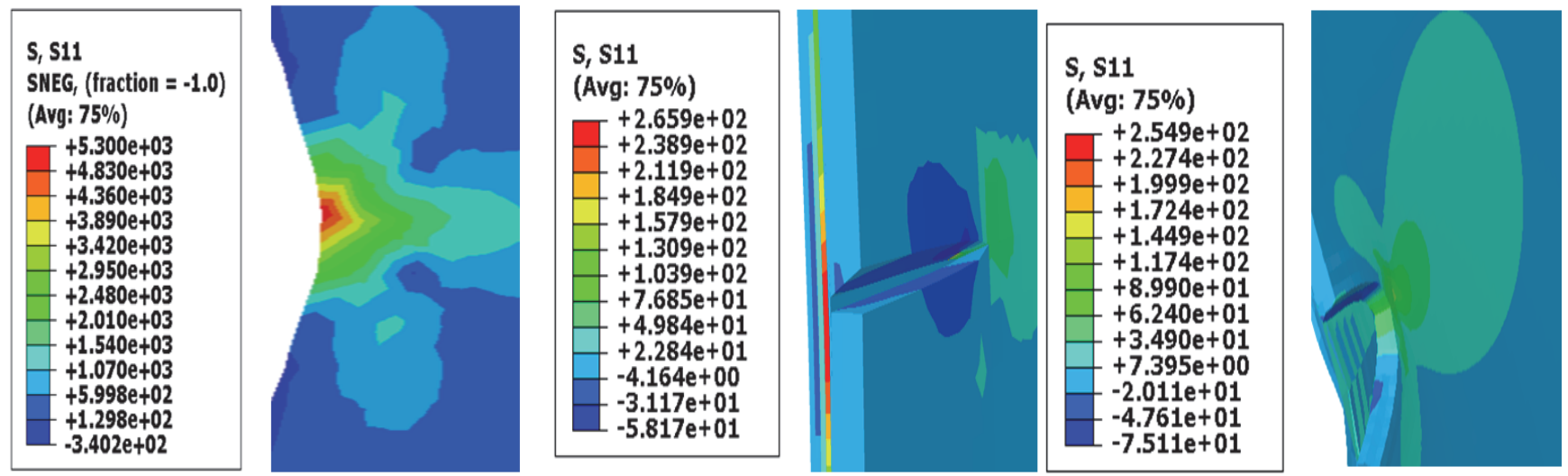

« Load 100 MPa»
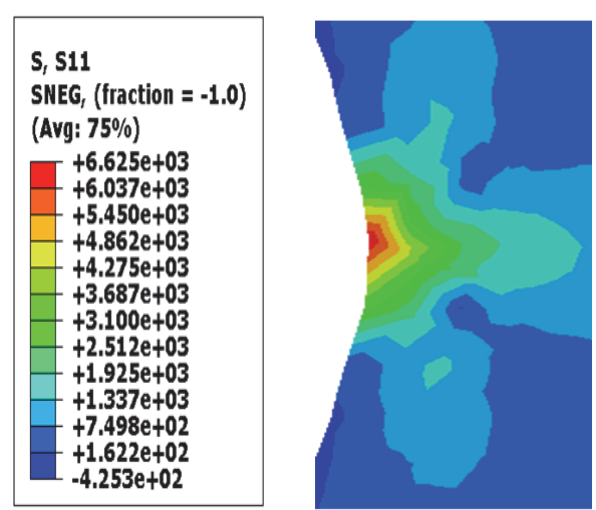

a)

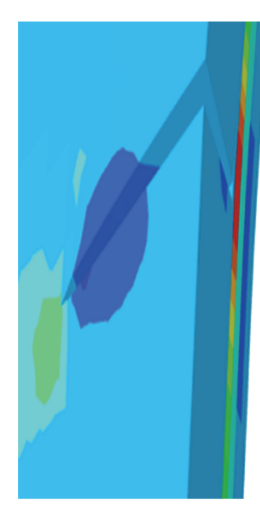

b)
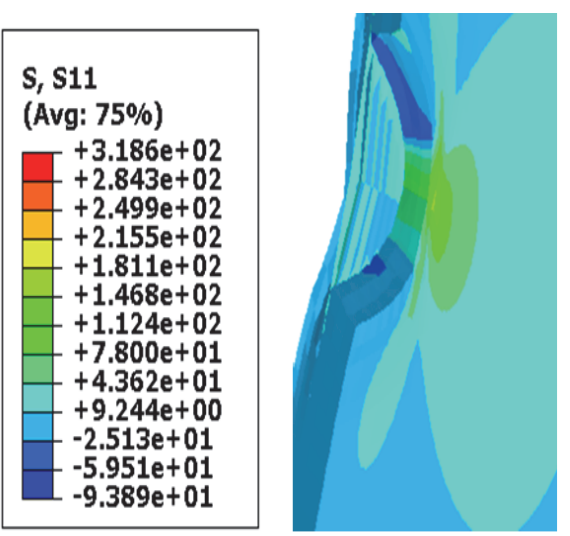

c)

Figure 6: Distribution of normal stresses бxx: a) Plate not repaired b) Plate repaired Boron epoxy c) Plate repaired Carbon epoxy.

To change the normal maximum stresses $\sigma x x$ according to different loads, we note that the repair patch composite provides a significant gain compared to the unrepaired plate and that depending on the corresponding patch, hence the effectiveness repair that extends the life of the cracked plate. The repair by these two composite patches is almost similar considering the two boron / epoxy and carbon / epoxy curves are almost combined and do not exceed 320MPa for a loading of $100 \mathrm{MPa}$. 

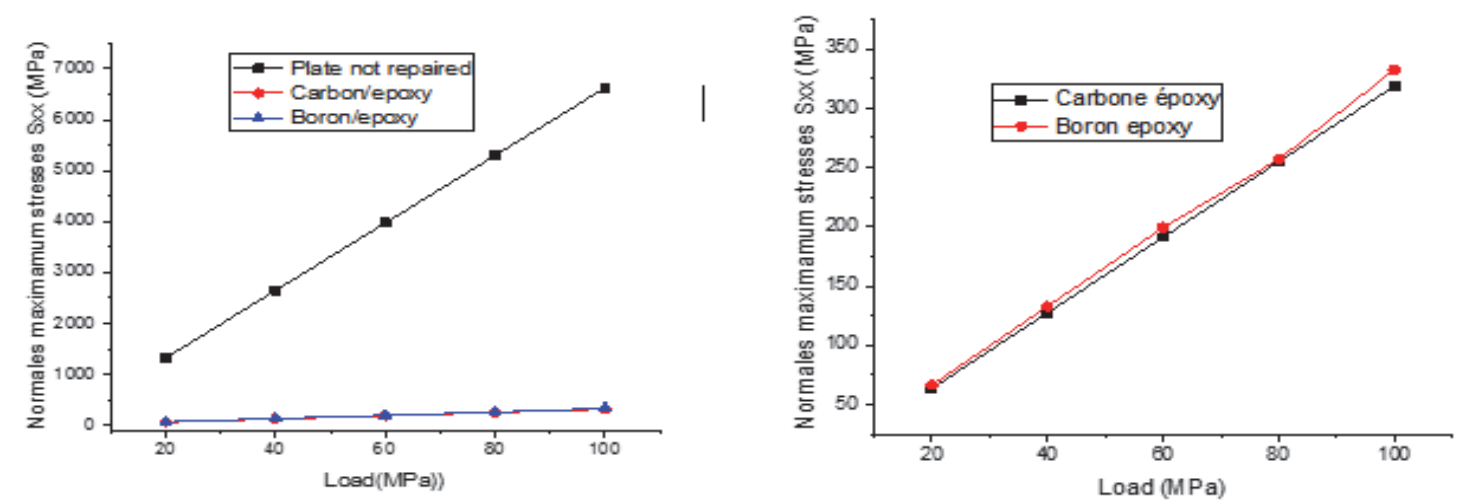

Figure 7: Variation of the maximum normal stresses $\sigma x x$ according to the various loadings

Shear stresses $\tau x y$

For the different loads, we compare the different tangential stresses for the unrepaired plate and after its repair by composite patch, which is Boron/Epoxy and Carbon/Epoxy; we have obtained the following results:

\begin{tabular}{|l|}
\hline S, S12 \\
SNEG, (fraction = -1.0) \\
(Avg: 75\%) \\
\hline$+1.493 \mathrm{e}+03$ \\
$+1.297 \mathrm{e}+03$ \\
$+1.100 \mathrm{e}+03$ \\
$+9.028 \mathrm{e}+02$ \\
$+7.060 \mathrm{e}+02$ \\
$+5.091 \mathrm{e}+02$ \\
$+3.123 \mathrm{e}+02$ \\
$+1.154 \mathrm{e}+02$ \\
$-8.141 \mathrm{e}+01$ \\
$-2.783 \mathrm{e}+02$ \\
$-4.751 \mathrm{e}+02$ \\
$-6.720 \mathrm{e}+02$ \\
$-8.688 \mathrm{e}+02$ \\
\hline
\end{tabular}

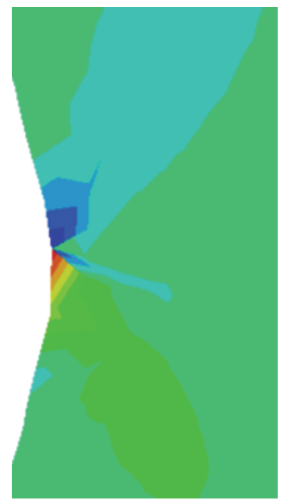

\begin{tabular}{|l|}
\hline S, S12 \\
(Avg: 75\%) \\
$+1.716 \mathrm{e}+01$ \\
$+1.336 \mathrm{e}+01$ \\
$+9.556 \mathrm{e}+00$ \\
$+5.752 \mathrm{e}+00$ \\
$+1.948 \mathrm{e}+00$ \\
$-1.856 \mathrm{e}+00$ \\
$-5.660 \mathrm{e}+00$ \\
$-9.463 \mathrm{e}+00$ \\
$-1.327 \mathrm{e}+01$ \\
$-1.707 \mathrm{e}+01$ \\
$-2.088 \mathrm{e}+01$ \\
$-2.468 \mathrm{e}+01$ \\
$-2.848 \mathrm{e}+01$ \\
\hline
\end{tabular}
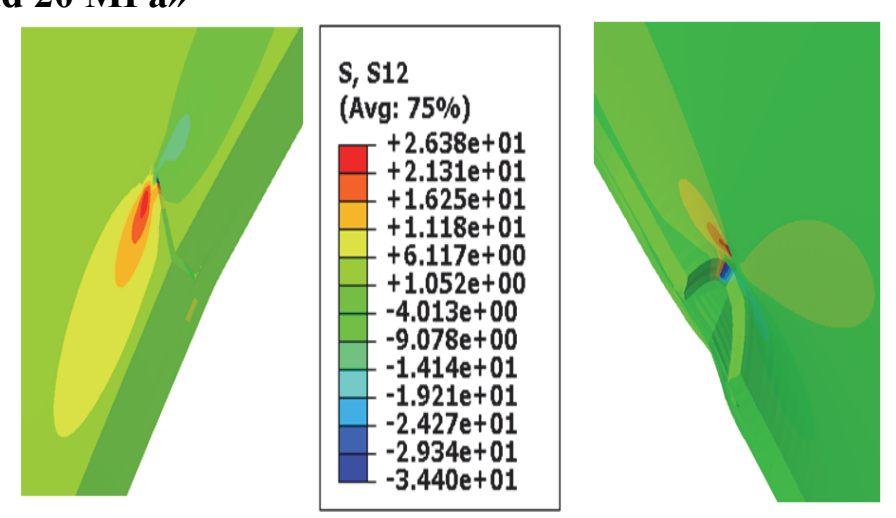

«Load 40 MPa»
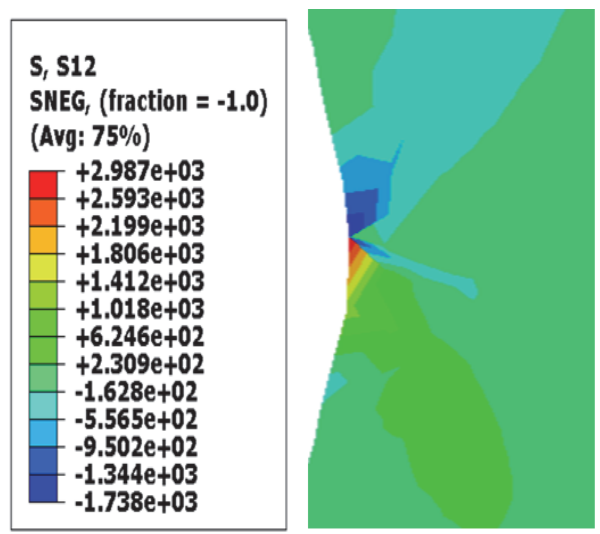

\begin{tabular}{|c|}
\hline $\begin{array}{l}\text { S, S12 } \\
\text { (Avg: 75\%) } \\
\begin{aligned}+3.433 \mathrm{e}+01 \\
+2.672 \mathrm{e}+01 \\
+1.911 \mathrm{e}+01 \\
+1.150 \mathrm{e}+01 \\
+3.897 \mathrm{e}+00 \\
+3.711 \mathrm{e}+00 \\
-1.132 \mathrm{e}+01 \\
-1.893 \mathrm{e}+01 \\
-2.653 \mathrm{e}+01 \\
-3.414 \mathrm{e}+01 \\
-4.175 \mathrm{e}+01 \\
-4.936 \mathrm{e}+01 \\
-5.697 \mathrm{e}+01\end{aligned}\end{array}$ \\
\hline
\end{tabular}
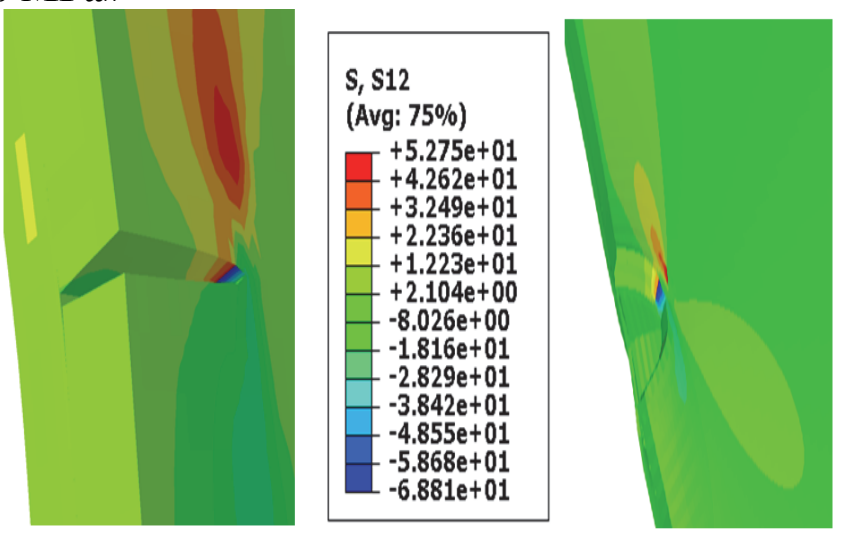
«Load 60 MPa»

\begin{tabular}{|l|}
\hline S, S12 \\
SNEG, (fraction = -1.0) \\
(Avg: 75\%) \\
\hline$+5.974 \mathrm{e}+03$ \\
$+5.186 \mathrm{e}+03$ \\
$+4.399 \mathrm{e}+03$ \\
$+3.611 \mathrm{e}+03$ \\
$+2.824 \mathrm{e}+03$ \\
$++2.037 \mathrm{e}+03$ \\
$+1.249 \mathrm{e}+03$ \\
$+4.617 \mathrm{e}+02$ \\
$-3.257 \mathrm{e}+02$ \\
$-1.113 \mathrm{e}+03$ \\
$-1.900 \mathrm{e}+03$ \\
$-2.688 \mathrm{e}+03$ \\
$-3.475 \mathrm{e}+03$ \\
\hline
\end{tabular}
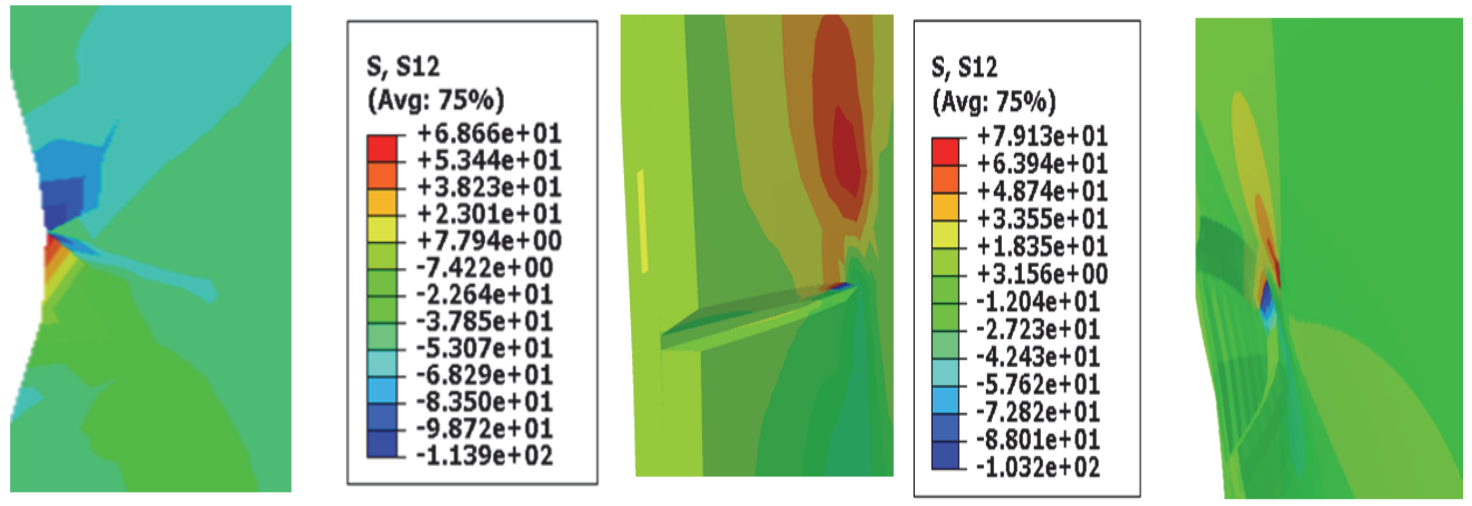

\section{«Load 80 MPa»}

\begin{tabular}{|l|}
\hline S, S12 \\
SNEG, (fraction = -1.0) \\
(Avg: 75\%) \\
$+7.467 \mathrm{e}+03$ \\
$+6.483 \mathrm{e}+03$ \\
$+\mathbf{5 . 4 9 8 \mathrm { e } + 0 3}$ \\
$+\mathbf{4}+514 \mathrm{e}+03$ \\
$++3.530 \mathrm{e}+03$ \\
$+2.546 \mathrm{e}+03$ \\
$+1.561 \mathrm{e}+03$ \\
$+5.772 \mathrm{e}+02$ \\
$-4.071 \mathrm{e}+02$ \\
$-1.391 \mathrm{e}+03$ \\
$-2.376 \mathrm{e}+03$ \\
$-3.360 \mathrm{e}+03$ \\
$-4.344 \mathrm{e}+03$ \\
\hline
\end{tabular}
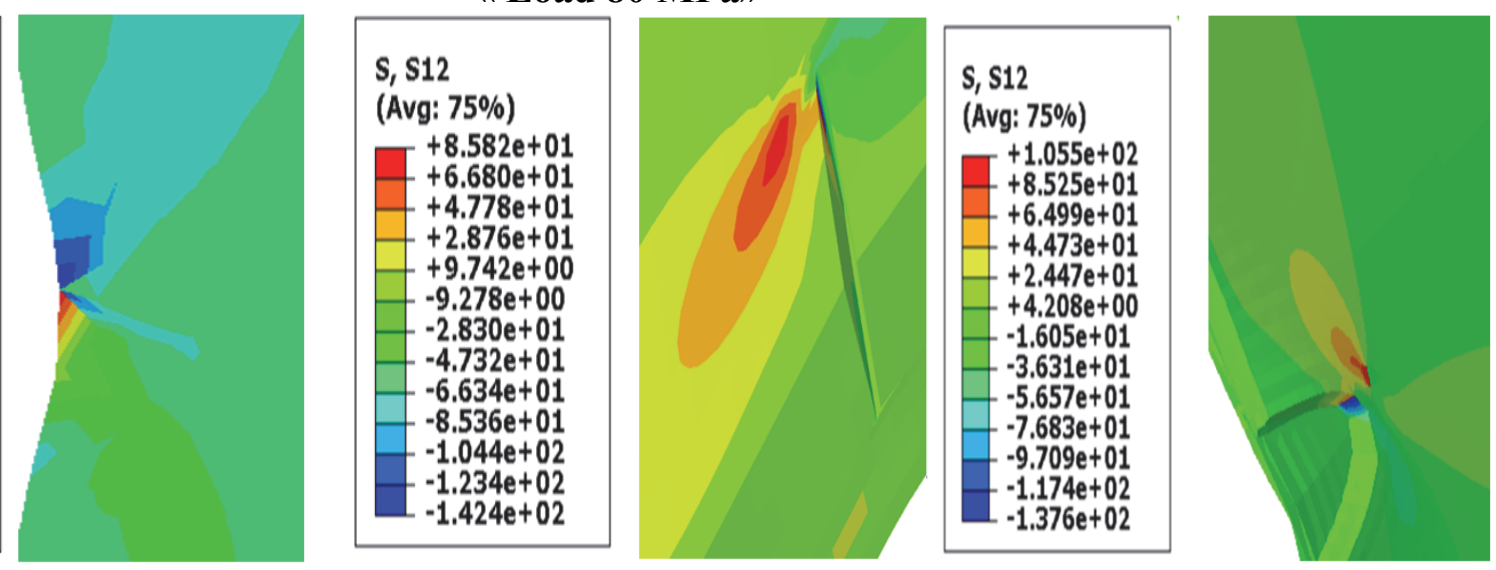

\section{«Load 100 MPa»}
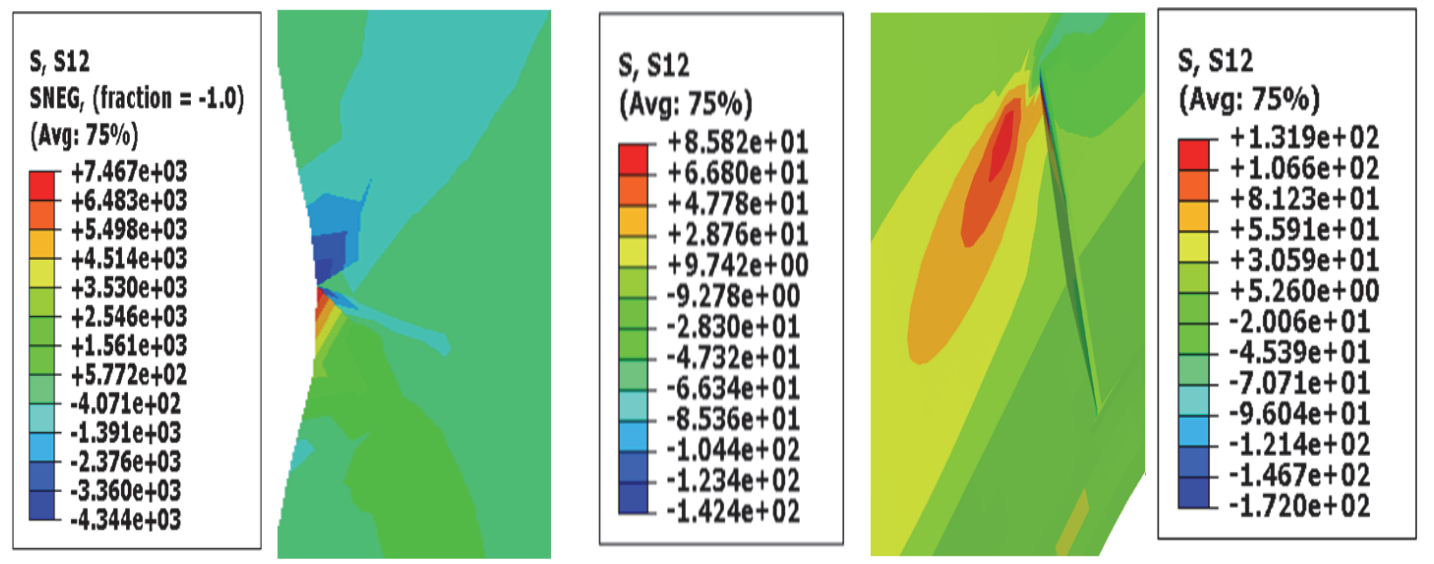

b)

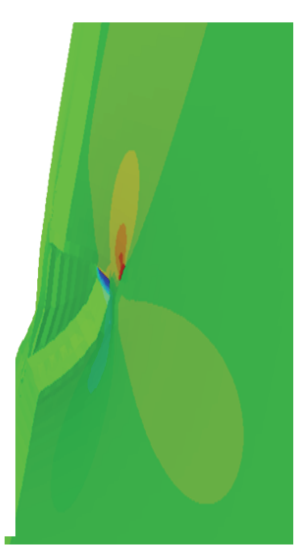

c)

Figure 8: Distribution of Shear stresses $\tau$ xy: a) Plate not repaired b) Plate repaired Boron epoxy c) Plate repaired Carbon epoxy

For the case of the tangential stresses which request a lot this cracked plate under a tension solicitation, the crack itself tends to be to initiate by the loading, and one can predict a propagation of this crack before the repair and for an ascending load, that us leads to repair by patch in composite by carbon / epoxy and boron / epoxy, this procedure has given satisfaction especially when the shear stresses have been absorbed in an impreciable way and allow the crack to attenuate its propagation, thus, to have a gain in lifespan relative to this plate before its repair. 

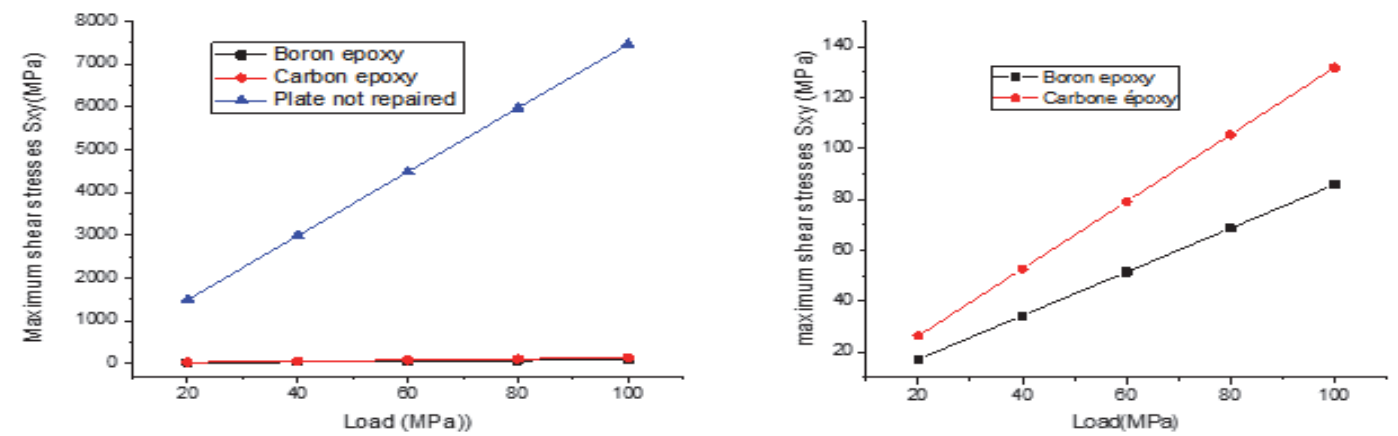

Figure 9: Variation of the maximum tangential stresses $\tau$ xy according to the various loadings.

For the paces of the curves representing the variation of the maximum shear stresses $\tau$ xy as a function of the different loadings, the gain in stresses going progressively from the unrepaired plate towards the plate repaired by the Carbon / epoxy patch, until the plate repaired by the most effective boron / epoxy composite , because the patch in boron / epoxy composite absorbs stress concentrations at the crack head well than the carbon/epoxy composite and consequently good stress absorption in the vicinity of the crack head.

\section{Normal stresses $\sigma y y$}

To be able to distinguish and see the effect of the patch on a cracked plate laterally stressed at tensile stresses of its two ends, that is to say, in the direction of the opening of the lips of the crack, we expose these normal constraints $\sigma y y$ for the two cases.
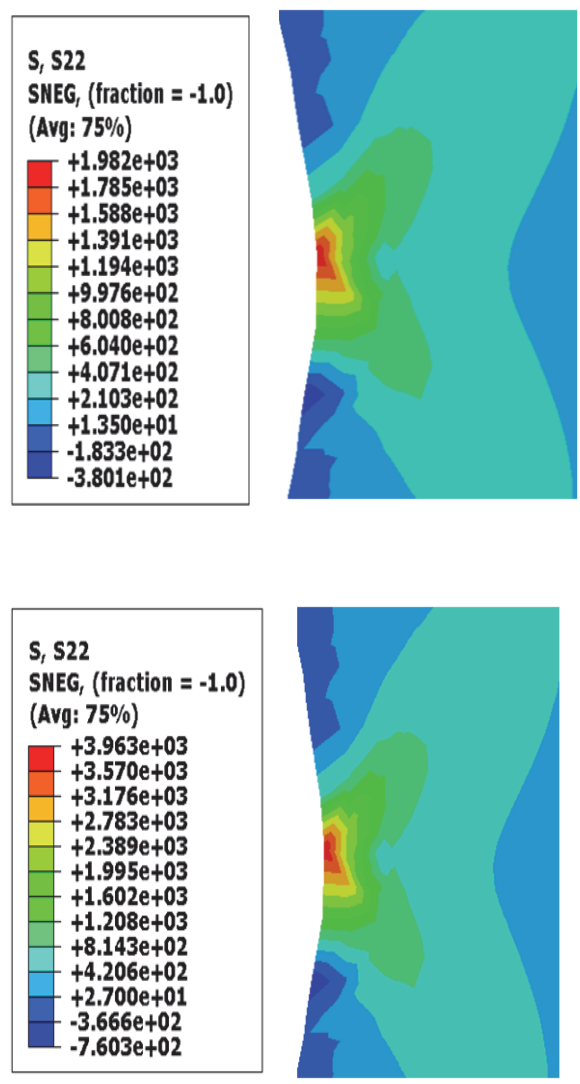

«Load 20 MPa»
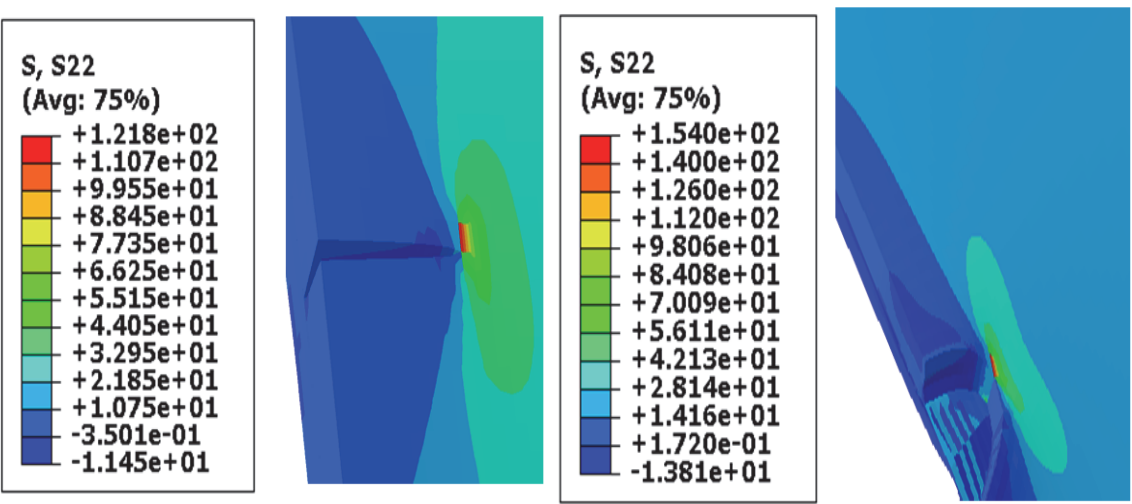

\section{«Load 40 MPa»}
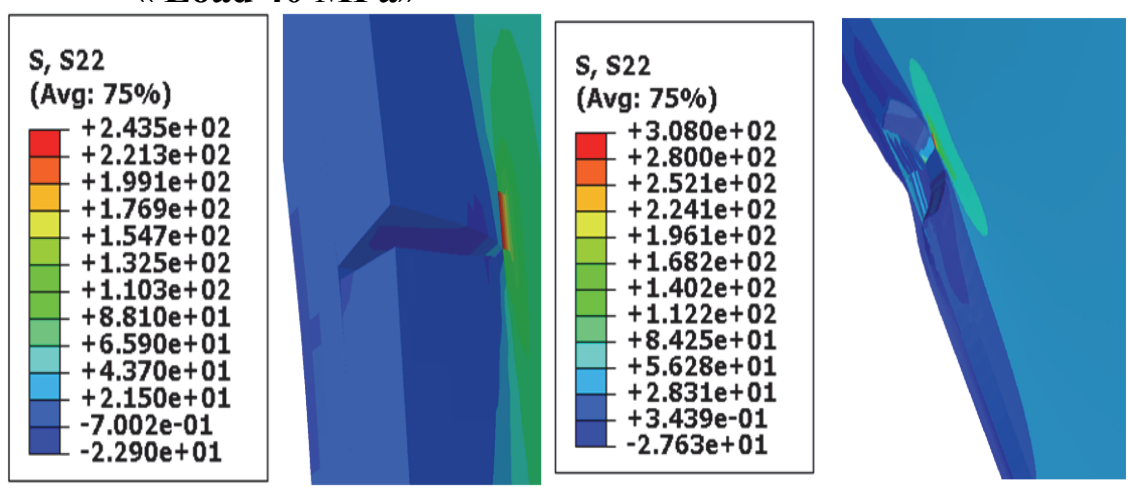
«Load 60 MPa»

\begin{tabular}{|l|}
\hline S, S22 \\
SNEG, (fraction = -1.0) \\
(Avg: 75\%) \\
\hline$+5.945 \mathrm{e}+03$ \\
$+5.355 \mathrm{e}+03$ \\
$+4.764 \mathrm{e}+03$ \\
$+4.174 \mathrm{e}+03$ \\
$++3.583 \mathrm{e}+03$ \\
$+2.993 \mathrm{e}+03$ \\
$+2.402 \mathrm{e}+03$ \\
$+1.812 \mathrm{e}+03$ \\
$+1.221 \mathrm{e}+03$ \\
$+6.310 \mathrm{e}+02$ \\
$+4.050 \mathrm{e}+01$ \\
$-5.500 \mathrm{e}+02$ \\
$-1.140 \mathrm{e}+03$ \\
\hline
\end{tabular}
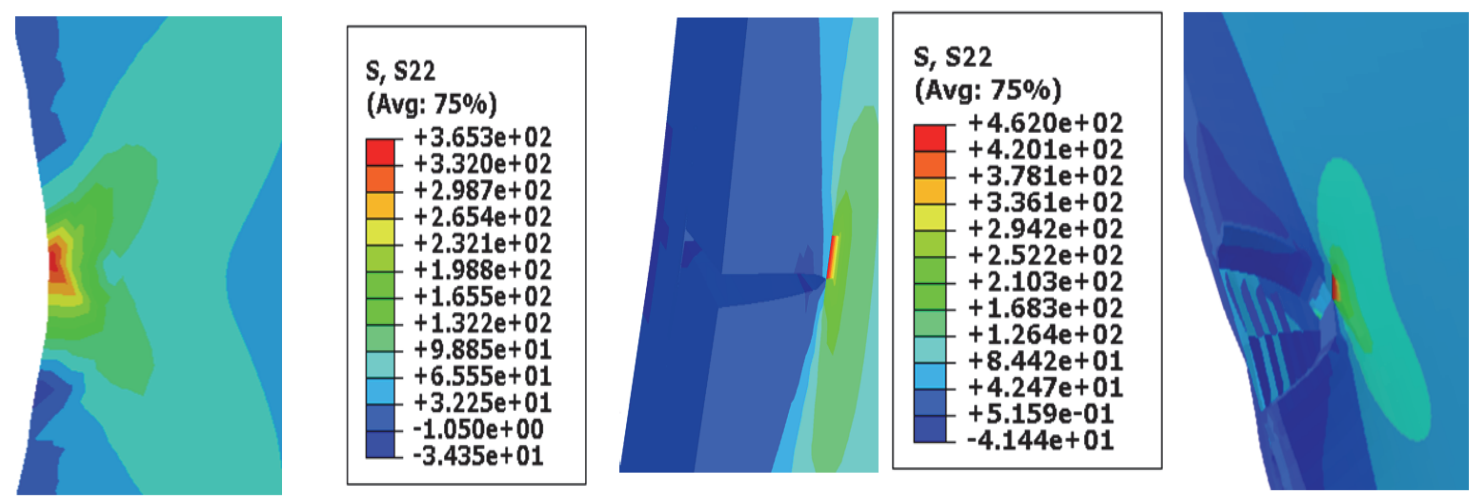

\section{«Load 80 MPa»}
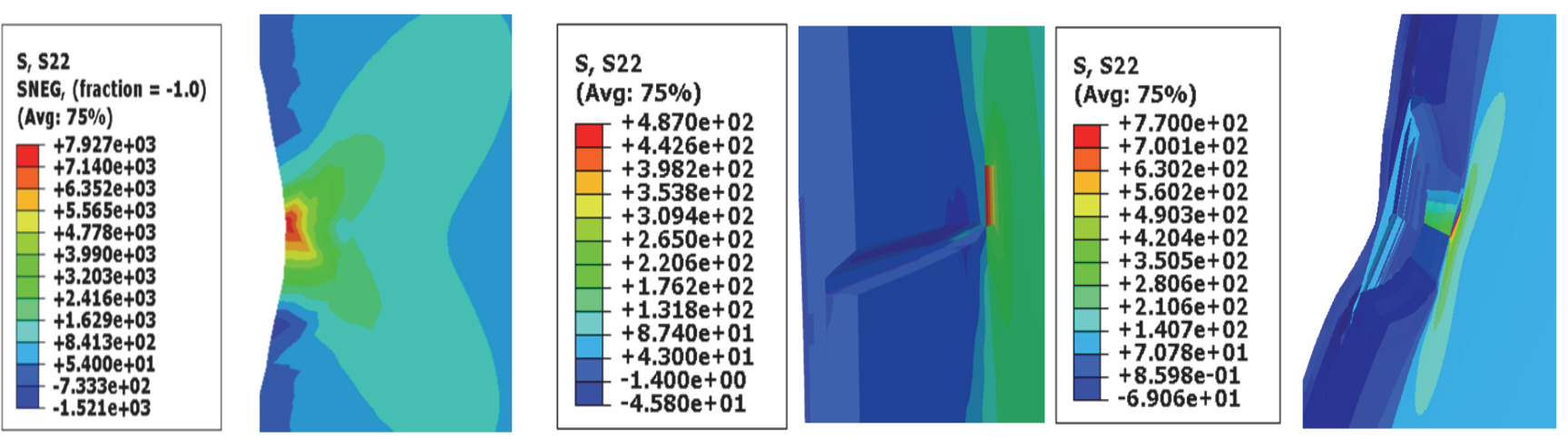

\section{«Load 100 MPa»}

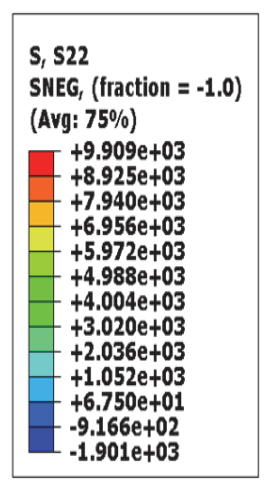

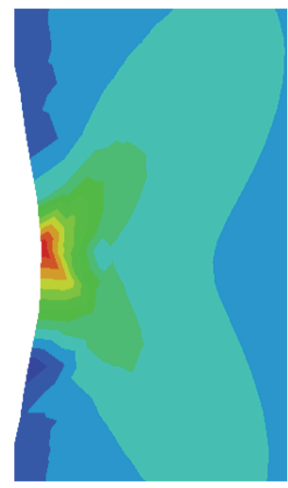

a)

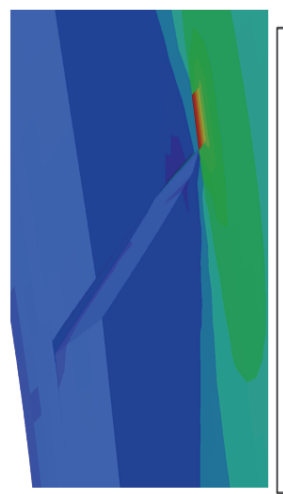

b)

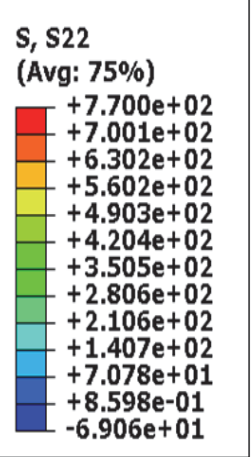

c)

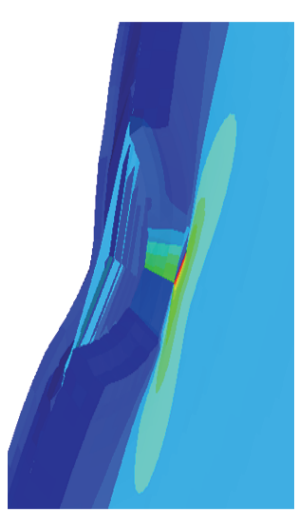

Figure 10: Distribution of normal stresses бyy: a) Plate not repaired b) Plate repaired Boron epoxy c) Plate repaired Carbon epoxy

The gain of the effect of the normal stresses $\sigma_{y y}$ is very remarkable, since the damping of these stresses is produced by this repair procedure by composite patch, by minimizing all the normal stresses induced in the vicinity of the crack head and making the affected area very confined, also absorbing the stress fields higher, and to avoid crack cracking.

We can conclude that the repair effect by composite patch is very distinct, given the stress intensities, which decrease for each repair; therefore, the composite patch dampens the field of stresses induced at the crack tip and causes a reduction in stresses. 

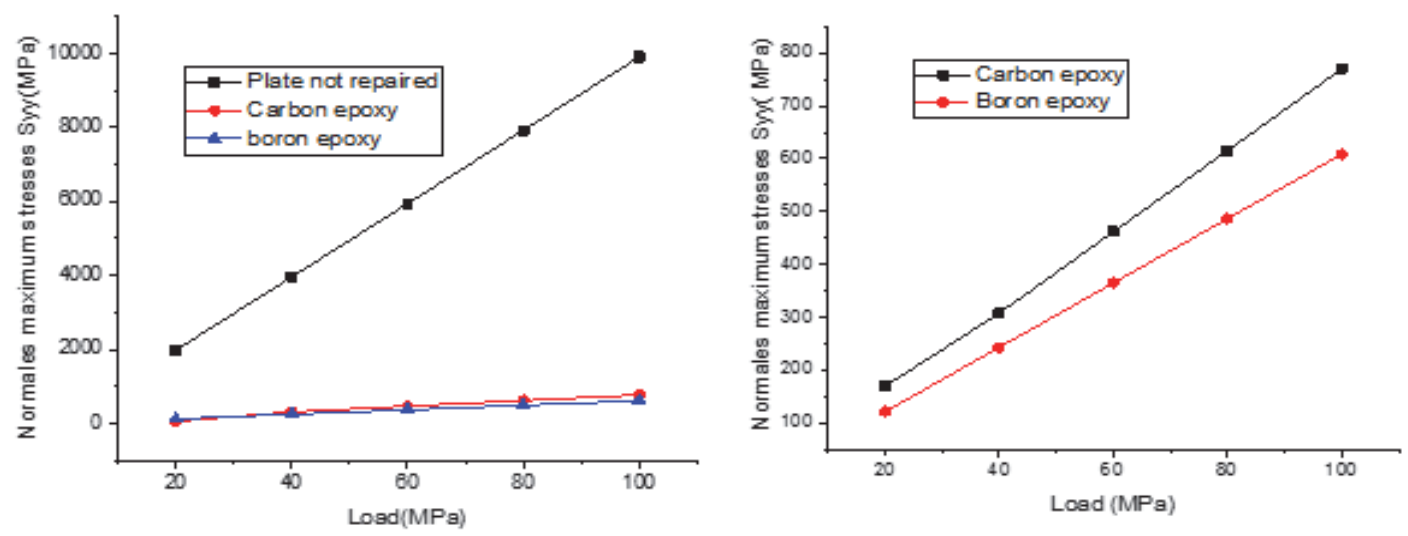

Figure 11: Variation of the maximum normal stresses $\sigma y y$ according to the various loadings

This figure shows that the effect of the repair by composite patch is very distinct; given the gain in the stresses, which experienced fairly low values relative to those found for the cracked plate without repair, therefore the composite patch is a damper or a stress absorber. The reduction of the stresses is very distinct for this not repaired plate by the effect of the repair by the two patches and it is very remarkable and more effective for the boron/epoxy, which presents better results for the reduction of the stresses and to prolong the service life of repaired materials.

\section{Integral J}

For the variation of the integral $\mathrm{J}$ as a function of each sequence (Plaice) for different loading for the plate repaired by patch in composite which is (Carbon / epoxy), we notice that as the load increases, the corresponding integral J also increases, and this integral reaches its maximum at sequence No. 2, that is to say for the orientation of the fibers at $45^{\circ}$, and this maximum value is of the order $5.3 \mathrm{mj} / \mathrm{mm}^{2}$.
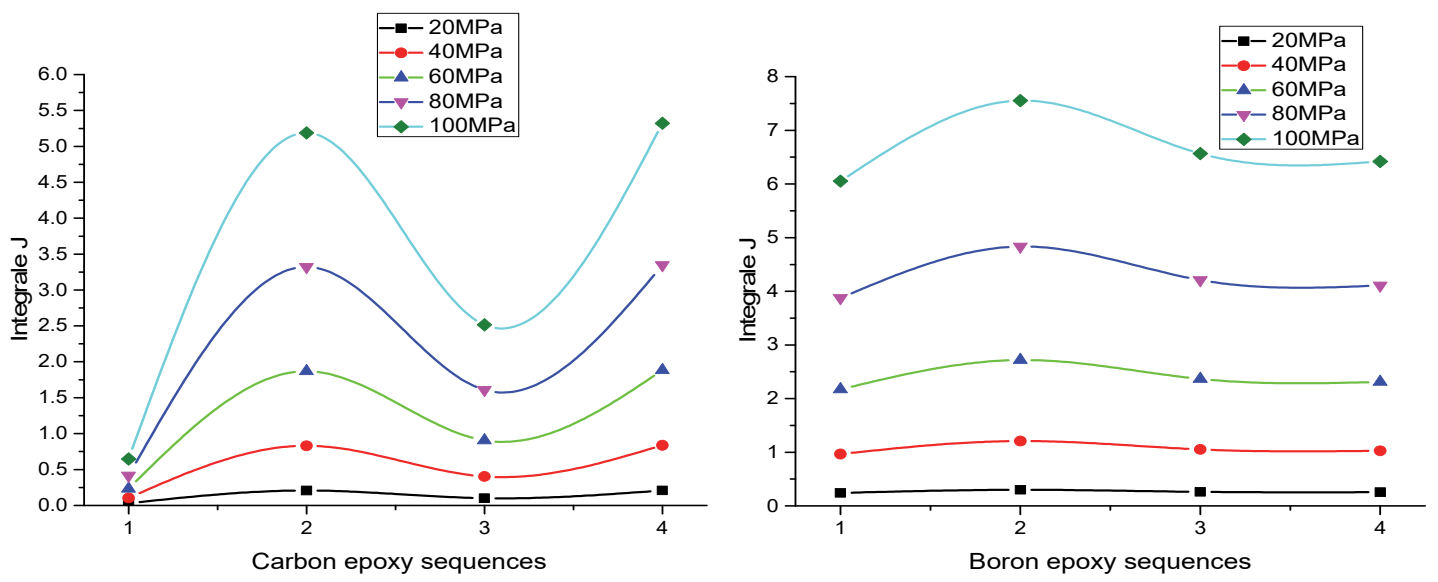

Figure 12: Representation of the integral (J) for different loading.

For the plate repaired by patch in composite (Boron epoxy), the variation of the integral $\mathrm{J}$ for different loads for the four stacking sequences is almost proportional to the loading, since for low loads such for $20 \mathrm{MPa}$ and $40 \mathrm{MPa}$, this integral does not exceed $2.7 \mathrm{mj} / \mathrm{mm}^{2}$, and reaches its peak which is of the order of $7.5 \mathrm{mj} / \mathrm{mm}^{2}$ for the same sequence with the orientation of the fibers at $45^{\circ}$, which corresponds to the second fold of the boron epoxy composite. in the close vicinity of the adhesive, the energy due to crack propagation, induces a greater intensity and for progressive loads and decreases towards the last stacking sequences of the patch, according to shows that the patch absorbs a very large amount energy that passes through it, and consequently, increase the lifetime of the structure. 


\section{CONCLUSION}

7 he reduction of the stress intensity by the composition patch repair is very significant at the crack front, which improves the fatigue of repaired aircraft structures. The repair performances are highly reduced for thick plate. It is recommended to repair thick plates with composite patch. The optimization of the geometrical properties of the adhesive and the patch can improve significantly the repair performances and durability. The use of multiple composite layers for repair can also improve the repair performances.

In this study, the following conclusions can be drawn:

- For the distribution of stresses for the various loads, we can conclude that the effect of the repair by patch in composite dampens the stress field induced at the bottom of the crack and involves a reduction of the stresses.

- The repair by Bore / Epoxy patch is more effective compared to the Carbon / epoxy patch, by its mechanical properties and by its specific characteristics, which gives very significant and very effective results.

- The most important stresses are the normal stresses $\sigma y y$ and the stresses of Von Mises, which are likely to delaminate the patch and to initiate the crack.

- The shear stresses $\tau_{\mathrm{xy}}$ have lower values compared to the other stresses, given the Adhesive: Adekit A-40, which has very effective bonding properties.

- The variation of the integral $\mathrm{J}$ for different loads for the four stacking sequences is almost proportional to the load, and reaches its peak, which is of the order of $7.5 \mathrm{mj} / \mathrm{mm}^{2}$ for the same sequence with the orientation fibers at $45^{\circ}$ for different contours in the vicinity of the crack head.

\section{REFERENCES}

[1] Pook, L. P. (1998). Geometric constraints on fatigue crack paths in tubular welded joints. The Archive of Mechanical Engineering, 45, pp. 143-156.

[2] Naebe, M., Abolhasani, M. M., Khayyam, H., Amini, A. and Fox, B. (2016). Crack damage in polymers and composites: A review. Polymer reviews, 56(1), pp. 31-69. DOI: 10.1080/15583724.2015.1078352.

[3] Bruzzi, M. S. and McHugh, P. E. (2004). Micromechanical investigation of the fatigue crack growth behaviour of AlSiC MMCs. International journal of fatigue, 26(8), pp. 795-804. DOI: 10.1016/j.ijfatigue.2004.01.007.

[4] Dan, Z. and Tuler, F. R. (1994). Effect of particle size on fracture toughness in metal matrix composites. Engineering fracture mechanics, 47(2), pp. 303-308.

[5] Flom, Y. and Arsenault, R. J. (1989). Effect of particle size on fracture toughness of SiC/Al composite material. Acta metallurgica, 37(9), pp. 2413-2423.

[6] Shang, J. K. and Ritchie, R. O. (1989). On the particle-size dependence of fatigue-crack propagation thresholds in SiCparticulate-reinforced aluminum-alloy composites: role of crack closure and crack trapping. Acta metallurgica, 37(8), pp. 2267-2278.

[7] Chen, Z. Z., Tokaji, K. and Minagi, A. (2001). Particle size dependence of fatigue crack propagation in SiC particulatereinforced aluminium alloy composites. Journal of materials science, 36(20), pp. 4893-4902. DOI: $10.1023 / \mathrm{A}: 1011884103226$

[8] Lee, C. S., Kim, J. H., Kim, S. K., Ryu, D. M. and Lee, J. M. (2015). Initial and progressive failure analyses for composite laminates using Puck failure criterion and damage-coupled finite element method. Composite Structures, 121, pp. 406419. DOI: $10.1007 / \mathrm{s} 11831-016-9191-2$.

[9] Mishnaevsky Jr, L. and Brøndsted, P. (2008). Three-dimensional numerical modelling of damage initiation in unidirectional fiber-reinforced composites with ductile matrix. Materials Science and Engineering: A, 498(1-2), pp. 8186. DOI: 10.1016/j.msea.2007.09.105.

[10] Souad, S., Serier, B., Bouafia, F., Bouidjra, B. A. B. and Hayat, S. S. (2013). Analysis of the stresses intensity factor in alumina-Pyrex composites. Computational materials science, 72, pp. 68-80. DOI: 10.1016/j.commatsci.2013.01.030.

[11] Tang, T., Hammi, Y., Horstemeyer, M. F. and Wang, P. (2012). Finite element micromechanical analysis of the deformation and stress state dependent damage evolution in fiber reinforced metal matrix composites. Computational materials science, 59, pp. 165-173. DOI: 10.1016/j.commatsci.2012.03.001.

[12] Bezzerrouki, M. (2019). Innovative geometric design improves the resistance of simple metal/metal lap joint. Frattura ed Integrità Strutturale, 13(48), pp. 491-502. DOI: 10.3221/IGF-ESIS.48.47. 
[13] Cheng, P., Gong, X. J., Hearn, D. and Aivazzadeh, S. (2011). Tensile behaviour of patch-repaired CFRP laminates. Composite structures, 93(2), pp. 582-589. DOI: 10.1016/j.compstruct.2010.08.021.

[14] Elajrami, M. and Slimani, M. E. A. (2019). Crack growth study under thermo-mechanical loads: parametric analysis for 2024 T3 aluminum alloy. Frattura ed Integrità Strutturale, 13(50), pp. 231-241. DOI: 10.3221/IGF- ESIS.50.19.

[15] Baker, A. A., Rose, L. F. and Jones, R. (Eds.). (2003). Advances in the bonded composite repair of metallic aircraft structure. Elsevier.

[16] Bianchi, R. W., Kwon, Y. W. and Alley, E. S. (2019). Composite Patch Repair for Underwater Aluminum Structures. Journal of Offshore Mechanics and Arctic Engineering, 141(6). DOI: 10.1115/1.4042940.

[17] Renzetti, F. R. and Zortea, L. (2011). Use of a gray level co-occurrence matrix to characterize duplex stainless steel phases microstructure. Frattura ed Integrita Strutturale, 5(16), pp. 43-51. DOI: 10.3221/IGF-ESIS.49.51.

[18] Her, S. C. and Chao, M. (2011). Adhesively bonded patch repair of composite laminates. Journal of adhesion science and technology, 25(18), pp. 2569-2585. DOI: 10.1163/016942411X580234.

[19] Turaga, V.R.S., Ripudiman. (1999). Modeling of patch repairs to a thin cracked sheet. Engn. Fract. Mec.74, pp. 431443.

[20] Liu, X. and Wang, G. (2007). Progressive failure analysis of bonded composite repairs. Composite Structures, 81(3), pp. 331-340. DOI: 10.1016/j.compstruct.2006.08.024.

[21] Bellini, C., Di Cocco, V., Iacoviello, F. and Sorrentino, L. (2019). Experimental analysis of aluminium/carbon epoxy hybrid laminates under flexural load. Frattura ed Integrità Strutturale, 13(49), pp. 739-747. DOI: 10.3221/IGF-ESIS.49.66.

[22] Wang, P., Lei, H., Zhu, X., Chen, H., Wang, C. and Fang, D. (2018). Effect of manufacturing defect on mechanical performance of plain weave carbon/epoxy composite based on 3D geometrical reconstruction. Composite Structures, 199, pp. 38-52. DOI : 10.1016/j.compstruct.2018.05.066.

[23] Xie, N., Smith, R. A., Mukhopadhyay, S. and Hallett, S. R. (2018). A numerical study on the influence of composite wrinkle defect geometry on compressive strength. Materials \& Design, 140, pp. 7-20. DOI:10.1016/j.matdes.2017.11.034.

[24] Lobanov, D. S., Wildemann, V. E., Spaskova, E. M. and Chikhachev, A. I. (2015). Experimental investigation of defects influence on composites sandwich panels strength using digital image correlation and infrared thermography methods. PNRPU Mechanics Bulletin, (4), pp. 159-170. DOI: 10.15593/perm.mech/2015.4.10.

[25] Serovaev, G. S. and Matveenko, V. P. (2016). Numerical study of the response of dynamic parameters to defects in composite structures. Frattura ed Integrità Strutturale, 10(38), pp. 392-398. DOI: 10.3221/IGF-ESIS.38.48.

[26] Tashkinov, M. A. (2017). Modelling of fracture processes in laminate composite plates with embedded delamination. Frattura ed Integrità Strutturale, 11(39), pp. 248-262. DOI: 10.3221/IGF-ESIS.39.23.

[27] Tretyakova, T. V., Wildemann, V. E., Strungar, E. M. and Tretyakov, M. P. (2018). Deformation and failure of carbon fiber composite specimens with embedded defects during tension-torsion test. Frattura ed Integrità Strutturale, 12(46), pp. 295-305. DOI: 10.3221/IGF-ESIS.46.2.

[28] Campagnolo, A., Berto, F. and Pook, L. P. (2015). Three-dimensional effects on cracked discs and plates under nominal Mode III loading. Frattura ed Integrità Strutturale, 9(34). DOI: 10.3221/IGF-ESIS.34.20.

[29] Madani, K., Touzain, S., Feaugas, X., Cohendouz, S. and Ratwani, M. (2010). Experimental and numerical study of repair techniques for panels with geometrical discontinuities. Computational Materials Science, 48(1), pp. 83-93. DOI: $10.1016 /$ j.commatsci.2009.12.005.

[30] ABAQUS/Standard Version 6.14-1. (2014). Analysis user's manual, Dassault Systémes Simulia Corporation,Providence, RI, (Hibbitt, Karlsson, Sorensen. Abaqus 6.14.1 Manual. 